\title{
A Study on the Composite Type Piezoelectric Motor
}

\author{
Jwo Ming Jou \\ Department of Mechanical Engineering, Cheng Shiu University, Kaohsiung City, Taiwan \\ Email: joujm@csu.edu.tw
}

Received July 13, 2013; revised August 13, 2013; accepted August 20, 2013

Copyright (C) 2013 Jwo Ming Jou. This is an open access article distributed under the Creative Commons Attribution License, which permits unrestricted use, distribution, and reproduction in any medium, provided the original work is properly cited.

\begin{abstract}
This study is to explore a composite type piezoelectric motor. Its main structures include the piezoelectric stator, rotor, the preload adjusting module and shaft. Wherein the piezoelectric stator is made base, the composite type actuating element and stator formed. As the composite type actuating element is set by the axial vibration type actuating element, horizontal bending vibration type actuating element and vertical bending vibration type actuating element formed. The stator is an empty cylinder with a waist and tapered hole. In addition, the rotor is a kind of a hollow cone. It can be through the preload adjusting module to withstand the stator. As the preload adjusting module is set by the limit element, spring, washer and nut formed. While the shaft is a kind of cylinder with screw thread and stopper, it can pass through the piezoelectric stator, rotor and the preload adjusting module, making it a composite type piezoelectric motor. When we provide appropriate driving voltage, frequency, loading and phase angle to the piezoelectric stator, we can let the piezoelectric motor produces rapid rotation. Of course, we can also change through the driving phase angle, to change the direction of rotation of the piezoelectric motor. According to the experimental results, we found that its maximum speed and loading are $480 \mathrm{rpm}$ and $2305 \mathrm{gw}$ under conditions of $180 \mathrm{~V}_{\mathrm{p}-\mathrm{p}}, 35 \mathrm{kHz}$ and $0^{0}$ driving phase angle. Most importantly, we also found that the composite type piezoelectric motor has a very good conversion efficiency of the driving phase angle.
\end{abstract}

Keywords: Composite Type Piezoelectric Motor; Axial Vibration Type Actuating Element; Horizontal Bending Vibration Type Actuating Element; Vertical Bending Vibration Type Actuating Element

\section{Introduction}

The ultrasonic motor was invented by Sadayuki Ueha and Minoru Kurosawa since 1988 [1], its maximum rotational speed and torque is $240 \mathrm{rpm}$ and $25 \mathrm{mNm}$ respectively. Over the past decade, there are still many different forms of piezoelectric motors or ultrasonic motors succession was invented, such as, a micro ultrasonic motor was invented by T. Kanda, A. Makino, K. Suzumori, T. Morita and M. K. Kurosawa [2], its maximum rotational speed is $3850 \mathrm{rpm}$, but its torque is only $2.5 \mathrm{nNm}$. In the same year, K.T. Chau [3], T. Kanda [4], Suzuki, A. Kihara [5], Yoichi Ogahara [6], Yosuke Nakagawa [7], etc., successively invented different forms of ultrasonic motor. Wherein, the ultrasonic motor was invented by Yosuke Nakagawa [7], its rotational speed is up to $800 \mathrm{rpm}$, and its torque is up to $0.25 \mathrm{Nm}$. In 2005 , after more than $2000 \mathrm{rpm}$ rotational speed of ultrasonic motors have been developed in succession [8-12]. In particular, the micro ultrasonic motor was invented by A. Kobayashi and T. Kanda in 2007 [10], and its rotational speed is up to $9600 \mathrm{rpm}$, and its torque is raised to 5.5
uNm.

In recent years, the new type piezoelectric motors or ultrasonic motors are constantly being innovative. For example, the 2011 year of invention, the multi-block piezoelectric car. Its main structure is a piezoelectric motor of $\mathrm{H}$-shaped and multi-layered form. Its maximum rotational speed and loading is respectively $432 \mathrm{rpm}$ and $496 \mathrm{gw}$ under conditions of $180 \mathrm{~V}_{\mathrm{p}-\mathrm{p}}$ and $19 \mathrm{kHz}$ [13]. In addition, the 2012 year of invention, the $\mathrm{H}$ type piezoelectric car. Its main structure is a piezoelectric motor of H-shaped and single layered form. Its maximum rotational speed and loading is respectively $2031 \mathrm{rpm}$ and $289 \mathrm{gw}$ under conditions of $180 \mathrm{~V}_{\mathrm{p}-\mathrm{p}}$ and $22.9 \mathrm{kHz}$ [14]. Under the same driving voltage condition, its rotational speed is 4.7 times the former, while its loading ability is only 0.58 times the former. In the same year, a piezoelectric motor of high actuating force, its loading ability is up to $590 \mathrm{gw}$, but the maximum rotational speed is only $53 \mathrm{rmp}$ under conditions of $180 \mathrm{~V}_{\mathrm{p}-\mathrm{p}}$ and $25.4 \mathrm{kHz}$ [15]. Until 2013, one kind of rod type ultrasonic motor, its loading ability can be increased to $4130 \mathrm{gw}$, and its rotational speed is up to $200 \mathrm{rmp}$ under conditions of 180 
$\mathrm{V}_{\mathrm{p}-\mathrm{p}}$ and $33.7 \mathrm{kHz}$ [16]. The piezoelectric motors or ultrasonic motors each having characteristics or advantages, the only drawback is that the phase angle conversion efficiency is poor. That is, the piezoelectric motors or ultrasonic motors are not easy to control rotational direction using the phase angle. The main purpose and motivation of the present study is through the innovative design of the piezoelectric motor to improve the conversion efficiency of the phase angle, and they can enhance the piezoelectric motor's rotational speed and loading ability.

\section{Composition and Operation Principle}

In order to improve the shortcoming of the above piezoelectric motors or ultrasonic motors, this study attempts to use a composite type piezoelectric motor, hoping to be able to improve the phase angle conversion efficiency and at the same time can improve its rotational speed and loading ability. The composite type piezoelectric motor is made by the composite type piezoelectric stator, rotor, preload adjusting module and shaft, shown as Figures 1 and 2. The composite type piezoelectric stator is composed of the base, the composite type piezoelectric actuating element and stator, shown as Figure 3. In addition, the preload adjusting module includes the limiting element, spring, washer and nut. As for the composite type piezoelectric actuating element is composed of the axial vibration type actuating element, the horizontal bending vibration type actuating element and the vertical bending vibration type actuating element, shown as Figure 4. When we applied different driving voltage, frequency and phase angle to the composite type piezoelectric actuating element, so that the rotor can produce clockwise or counterclockwise rotation, shown as Figure 5.

\section{The Trajectory of the Piezoelectric Stator}

In this study, a composite type piezoelectric motor, its main structure comprises a piezoelectric stator, rotor, preload adjusting module and shaft. However, the decision to motion behavior (including rotational speed and direction) of a piezoelectric motor is piezoelectric stator. So long as we know the vibration modes or trajectory of the piezoelectric stator, you can know the motion behaveior of the piezoelectric motor.

Since the rotor is by the optimum vibration mode or trajectory of the piezoelectric stator to the friction rotation under condition of an appropriate preload or loading. Based on past experience, we can understand the optimal trajectory of the piezoelectric stator is a solid elliptical orbit [16], as:

$$
\left(\frac{u}{U_{m}}\right)^{2}+\left(\frac{v}{V_{m}}\right)^{2}+\left(\frac{w}{W_{m}}\right)^{2}=1 .
$$

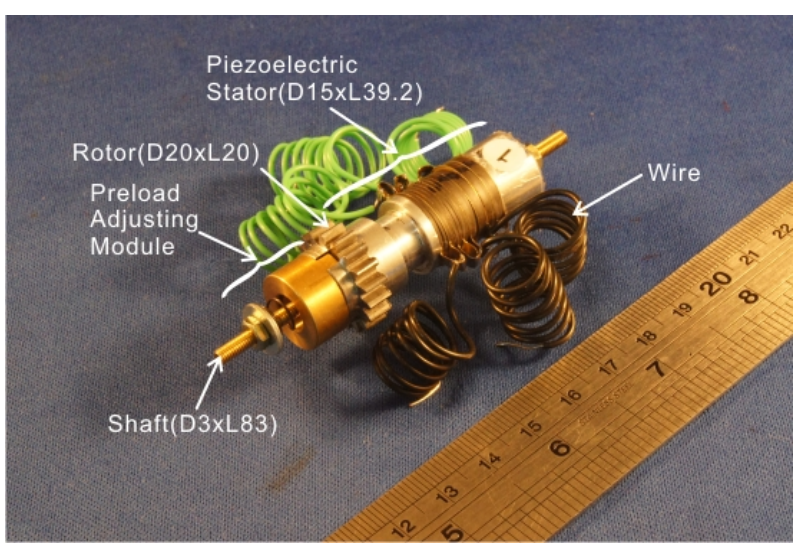

Figure 1. The prototype of the composite type piezoelectric motor.

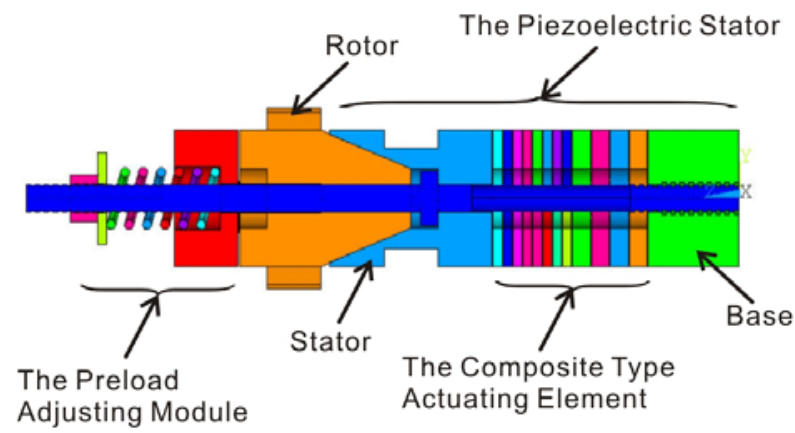

Figure 2. The cutaway view of the composite type piezoelectric motor.

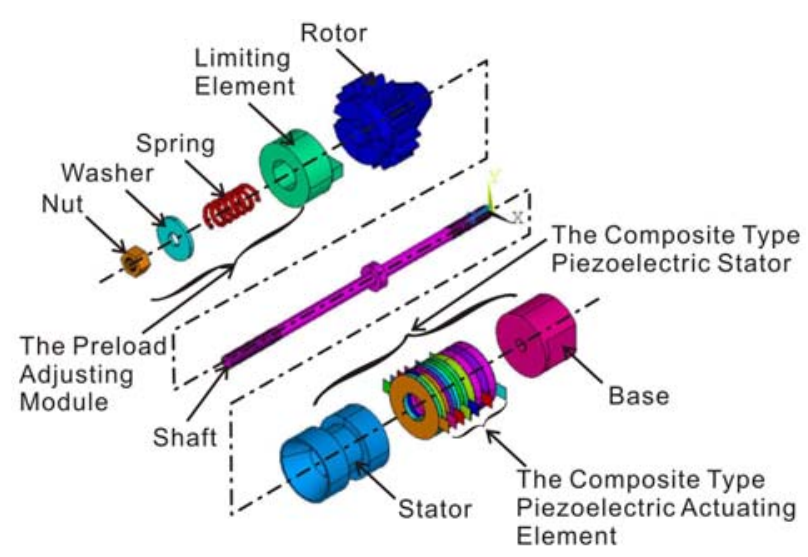

Figure 3. The exploded view of the composite type piezoelectric motor.

where

$$
\begin{gathered}
u=U_{m} \sin \left(\omega_{m} t+\phi\right) \sin \omega_{m} t . \\
v=V_{m} \cos \left(\omega_{m} t+\phi\right) \sin \omega_{m} t . \\
w=W_{m} \cos \omega_{m} t .
\end{gathered}
$$

and

$$
U_{m}=c_{x i} d_{3 i} V_{p-p} .
$$




$$
\begin{aligned}
& V_{m}=c_{y i} d_{3 i} V_{p-p} . \\
& W_{m}=c_{z i} d_{3 i} V_{p-p} .
\end{aligned}
$$

where $\boldsymbol{u}, \boldsymbol{v}$, and $\boldsymbol{w}$ represent the different direction of displacement separately, and where $U_{m}, V_{m}$ and $W_{m}$ represent the amplitude of the horizontal, vertical and longitudinal direction separately. $\omega_{m}\left(=2 \pi f_{m}\right)$ represents driving angle velocity, where $f_{m}$ representatives resonance frequency, and $\phi$ driving phase angle. Where $c_{x i}, c_{y i}$ and $c_{z i}$ represents horizontal, vertical and longitudinal direction out of revise coefficient tensor separately, and where the subscript $i=1,2,3 . d_{3 i}$ represents piezoelectric strain constant of $d$-form, such as $d_{31}, d_{32}$ and $d_{33}$.

\section{Simulation and Experiment}

In this study, we selected five different lengths of piezoelectric stators to simulate, shown as Figure $\mathbf{6}$ and Table 1, wherein the base and stator is made of aluminum. While the composite type piezoelectric actuating element is made of PZT and copper slices. Since copper is very thin, so the computer simulation to be ignored. The physical properties of the piezoelectric stator expressed in Table 2.

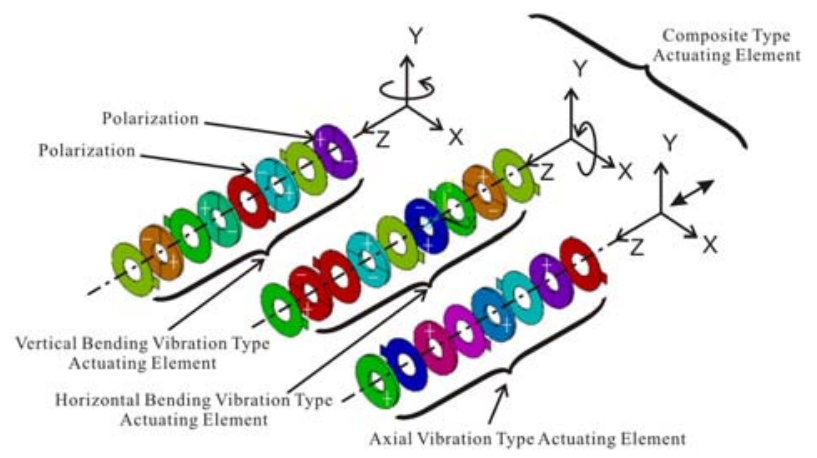

Figure 4. The exploded view of the composite type actuating Element.

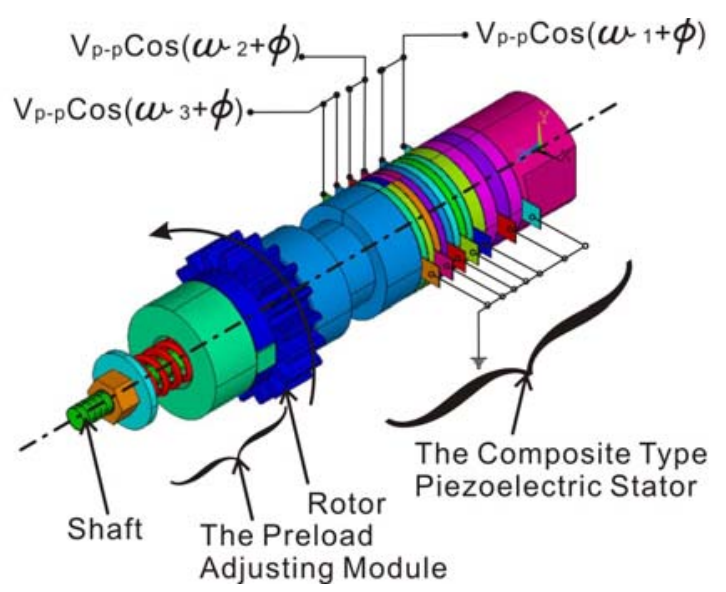

Figure 5. The composition and operation principle of the composite type piezoelectric motor.

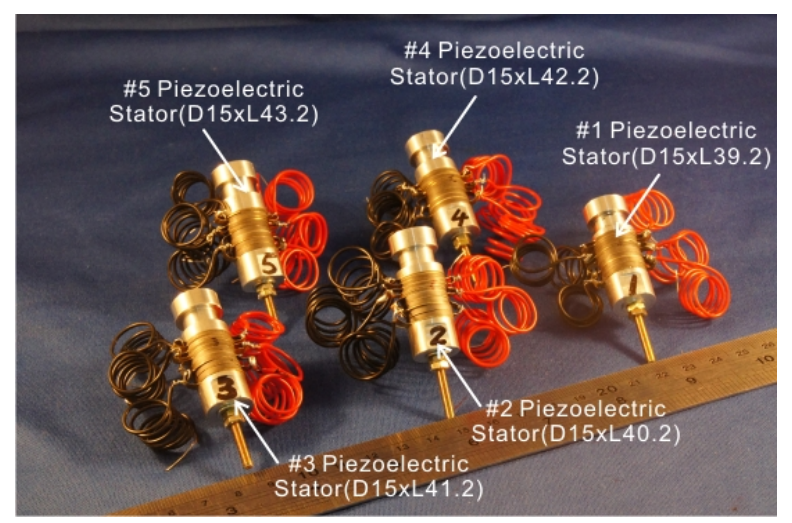

Figure 6. The \#1 - \#5 composite type piezoelectric stators.

Table 1. The net weight and size of piezoelectric stators.

\begin{tabular}{ccc}
\hline TYPE & Net Weight $(\mathrm{GW})$ & SizE $(\mathrm{MM})$ \\
\hline$\# 1$ & 32.2 & $\mathrm{D} 15 \times \mathrm{L} 39.2$ \\
$\# 2$ & 32.7 & $\mathrm{D} 15 \times \mathrm{L} 40.2$ \\
$\# 3$ & 33.1 & $\mathrm{D} 15 \times \mathrm{L} 41.2$ \\
$\# 4$ & 33.6 & $\mathrm{D} 15 \times \mathrm{L} 42.2$ \\
$\# 5$ & 34.0 & $\mathrm{D} 15 \times \mathrm{L} 43.2$ \\
\hline
\end{tabular}

\begin{tabular}{|c|c|c|}
\hline MATERAIL & PHYSICAL NAME & PHYSICAL QUANTITIES \\
\hline \multirow{5}{*}{$\begin{array}{c}\text { ACTUATING } \\
\text { ELEMENT } \\
\text { (PIEZOELECTRIC } \\
\text { CERAMIC } \\
\text { SLICE_PZT5) }\end{array}$} & $\begin{array}{l}\text { PIEZOELECTRIC } \\
\text { STRAIN } \\
\text { CONSTANTS }\end{array}$ & $\begin{array}{c}\mathrm{D} 31=\mathrm{D} 32=-274(\mathrm{PM} / \mathrm{V}) \\
\mathrm{D} 33=593(\mathrm{PM} / \mathrm{V}) \\
\mathrm{D} 15=\mathrm{D} 24=741(\mathrm{PM} / \mathrm{V})\end{array}$ \\
\hline & PERMITTIVITY & $\begin{array}{c}\mathrm{E} 11=\mathrm{E} 22=15.3(\mathrm{NF} / \mathrm{M}) \\
\mathrm{E} 33=15.1(\mathrm{NF} / \mathrm{M})\end{array}$ \\
\hline & $\begin{array}{l}\text { PIEZOELECTRIC } \\
\text { STRESS } \\
\text { CONSTANTS }\end{array}$ & $\begin{array}{c}\mathrm{E} 31=\mathrm{E} 32=-5.3(\mathrm{~N} / \mathrm{VM}) \\
\mathrm{E} 33=15.8(\mathrm{PM} / \mathrm{V}) \\
\mathrm{E} 15=\mathrm{E} 24=12.3(\mathrm{PM} / \mathrm{V})\end{array}$ \\
\hline & $\begin{array}{l}\text { STIFFNESS } \\
\text { CONSTANTS }\end{array}$ & $\begin{array}{c}\mathrm{C} 11=\mathrm{C} 22=120(\mathrm{GPA}), \\
\mathrm{C} 33=111(\mathrm{GPA}) \\
\mathrm{C} 44=30(\mathrm{GPA}), \\
\mathrm{C} 55=\mathrm{C} 66=26(\mathrm{GPA}), \\
\mathrm{C} 12=\mathrm{C} 21=75.2(\mathrm{GPA}) \\
\mathrm{C} 13=\mathrm{C} 31=\mathrm{C} 23=\mathrm{C} 32=75.1 \\
(\mathrm{GPA})\end{array}$ \\
\hline & DENSITY & $\mathrm{P}=7700(\mathrm{KG} / \mathrm{M} 3)$ \\
\hline \multirow{3}{*}{$\begin{array}{l}\text { BASE \& STATOR } \\
\quad\left(6061 \_A L\right)\end{array}$} & $\begin{array}{l}\text { YounG's } \\
\text { MODULuS }\end{array}$ & $\mathrm{E}=73 \mathrm{GPA}$ \\
\hline & POISSON RATIO & $\mathrm{N}=0.33$ \\
\hline & DENSITY & $\mathrm{P}=2700(\mathrm{KG} / \mathrm{M} 3)$ \\
\hline
\end{tabular}

Table 2. The physical properties of piezoelectric stators.

In computer simulation, we use the ANSYS code. As the element type, we choose the solid 98 or couple field and the smart size, we choose the 6th size for all materials. The mechanical boundary condition is clamped-free. As regards the electrical boundary, conditions are open circuit.

In the experiment, we used rotors of different shapes, sizes, weight and materials, as shown in Figures 7 and 8 and Table 3. To drive the rotor, we use the power ampli- 


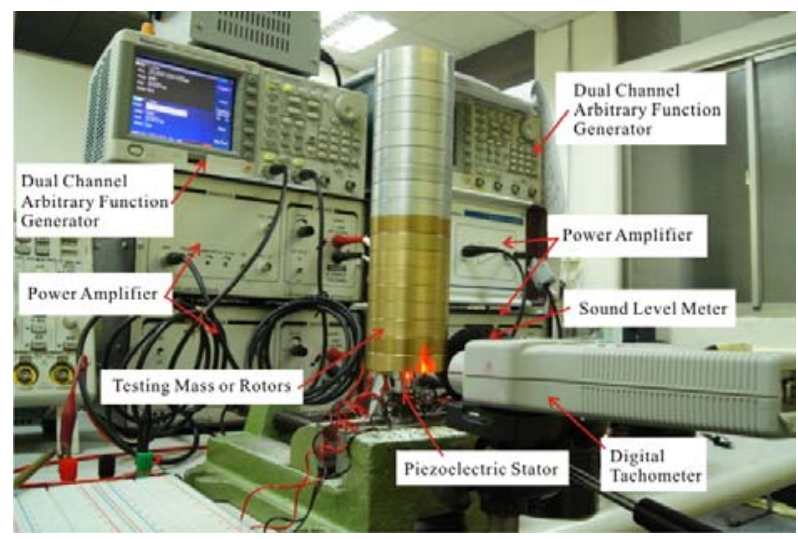

Figure 7. The experimental structure of the composite type piezoelectric stator.

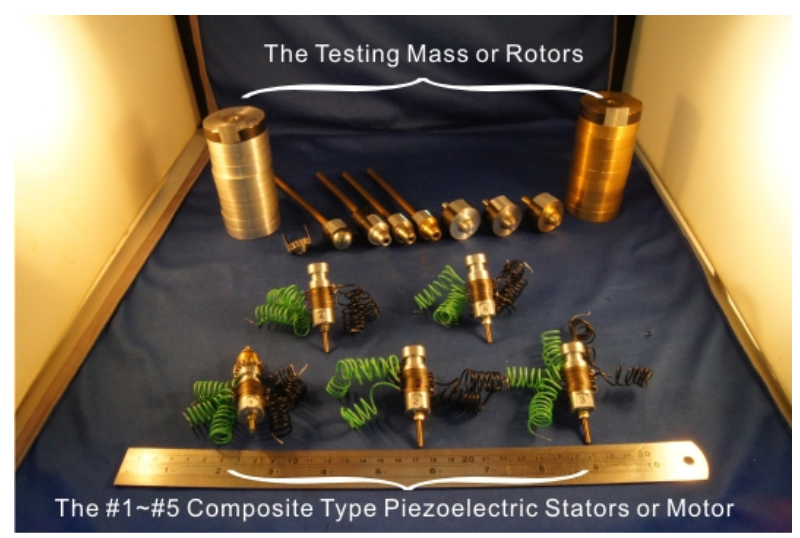

Figure 8. The testing mass or rotors and the \#1 - \#5 composite type piezoelectric stators or motor.

Table 3. The net weight and size of testing rotors.

\begin{tabular}{|c|c|c|c|}
\hline TESTING ROTORS & $\begin{array}{c}\text { NeT } \\
\text { WEIGHT (GW) }\end{array}$ & $\begin{array}{l}\text { SIZE } \\
(\mathrm{MM})\end{array}$ & $\begin{array}{c}\text { ABBREVIATION } \\
\text { OR CODE }\end{array}$ \\
\hline GEAR TYPE & 12.1 & $\mathrm{D} 20 \times \mathrm{L} 10.0$ & D20GEAR \\
\hline BALL TYPE & 58.6 & $\mathrm{D} 20 \times \mathrm{L} 170$ & D20BALL \\
\hline $\begin{array}{l}6061 \text { ALUMINUM } \\
\text { CONICAL TYPE }\end{array}$ & 58.6 & $\mathrm{D} 20 \times \mathrm{L} 150$ & D20AL \\
\hline $\begin{array}{c}304 \text { STEEL } \\
\text { CONICAL TyPe }\end{array}$ & 58.6 & $\mathrm{D} 20 \times \mathrm{L} 147$ & D20ST \\
\hline $\begin{array}{c}\text { COPPER } \\
\text { CONICAL TYPE }\end{array}$ & 58.6 & $\mathrm{D} 20 \times \mathrm{L} 146$ & D20CU \\
\hline $\begin{array}{l}6061 \text { ALUMINUM } \\
\text { CONICAL TYPE }\end{array}$ & 33.3 & $\mathrm{D} 30 \times \mathrm{L} 44$ & D30AL \\
\hline $\begin{array}{c}304 \text { STEEL } \\
\text { CONICAL TYPE }\end{array}$ & 95.6 & $\mathrm{D} 30 \times \mathrm{L} 44$ & D30ST \\
\hline $\begin{array}{c}\text { COPPER CONICAL } \\
\text { TYPE }\end{array}$ & 103.9 & $\mathrm{D} 30 \times \mathrm{L} 44$ & $\mathrm{D} 30 \mathrm{CU}$ \\
\hline
\end{tabular}

fier (Model: A-303, AA Lab. Systems Ltd. Co.) and the dual channel arbitrary function generator (Model: AFG3022, Tektronix Co.). As for the rotational speed measurement, we use the digital tachometer (Model: RM-
1501, TES Electrical Electronic Co.). When the noise in the measurements, we used the sound level meter (Model: TES 1350A, TES Electrical Electronic Co.).

\section{Results and Discussion}

According to the results of simulations and experiments, we found:

1) Figure 9 shows the results of the computer simulation analysis; we found that the resonance frequency is inversely proportional to the length of the stator. That is, the longer the length of the stator, the lower its resonant frequency. The first resonance mode frequency is 11.664 $\mathrm{kHz}$ of the \#1 piezoelectric stator. The first resonance mode frequency is $9.361 \mathrm{kHz}$ of the $\# 5$ piezoelectric stator, wherein, the first resonance frequency is a vertical bending vibration mode for the \#1 - \#5 piezoelectric stators. The second resonance frequency is a horizontal bending vibration mode. As for, the third resonance frequency is an axial (or longitudinal) vibration mode. In addition, the fourth and fifth resonance frequency is respectively a horizontal and vertical bending vibration mode of the \#1 - \#5 stators. At last, the sixth and seventh is respectively coupling bending vibration mode.

2) Figure 10 shows the results of the computer simulation analysis; we found that the maximum deformation is inversely proportional to the length of the stator. That is, under the same resonant mode, the longer the length of the stator, that the maximum deformation is smaller. Also, we can through the maximum deformation of the vibration modes to find the best driving or resonant frequency of piezoelectric motor.

3) As shown in Figures 11 to 15, the results of the computer simulation analysis, we find the best vibration mode of each piezoelectric stator landed between fourth or fifth resonance frequencies. The free end or top end of the best vibration mode is fully compatible with Equation (1) as described in elliptical trajectory.

4) Figure 16 shows the experimental results, we found that the rotational speed of the driving way of three kinds of vibration modes is better than the other. Where the maximum rotational speed is up to $480 \mathrm{rpm}$ under conditions of the driving way of three vibration modes, 180 $\mathrm{V}_{\mathrm{p}-\mathrm{p}}$ driving voltage, $35 \mathrm{kHz}$ driving frequency, $12.1 \mathrm{gw}$ preload and gear type rotor. In which, the driving way of three kinds of vibration modes including axial vibration (or longitudinal), horizontal bending, and vertical bending vibration mode.

5) Figure 17 shows the experimental results, we found that the driving way of three kinds of vibration modes, which the average noise is much lower than the other driving way. Where the average noise is $71 \mathrm{~dB}$ of the driving way of three vibration modes under conditions of $180 \mathrm{~V}_{\mathrm{p}-\mathrm{p}}$ driving voltage, $35 \mathrm{kHz}$ driving frequency, 12.1 gw preload and gear type rotor. Where the higher noise 


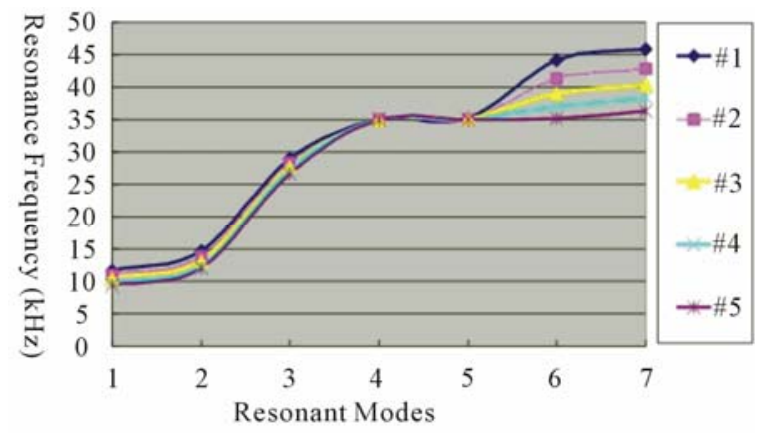

Figure 9. The resonance frequency relative to the resonant modes of the \#1 - \#5 composite type piezoelectric stator.

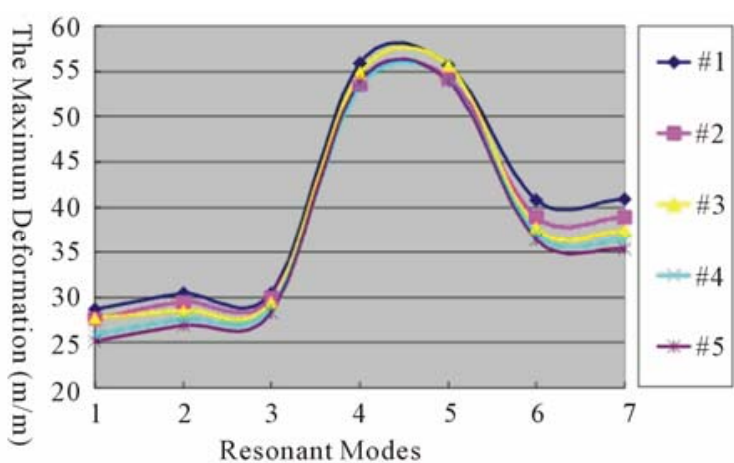

Figure 10. The maximum deformation relative to the resonant modes of the \#1 - \#5 composite type piezoelectric stator.

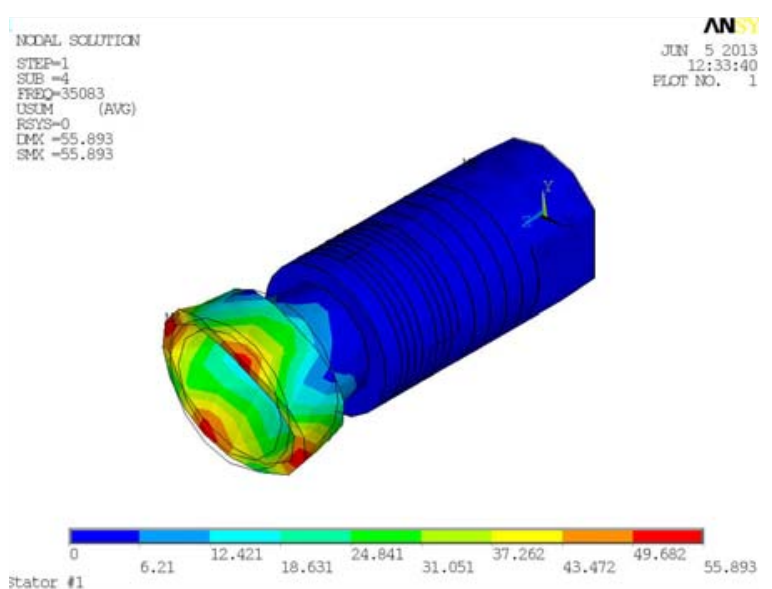

Figure 11. The best vibration mode of the \#1 composite type piezoelectric stator.

values for all driving ways appear in the $20 \mathrm{kHz}$ before.

6) As shown in Figures 18 to 19 results, no matter what kind driving condition, we find the conversion efficiency of the driving phase angle of the \#1 piezoelectric stator is better than the other. For the rotational speed, where the L\&HB: $0^{\circ}$ and VB: $0^{\circ}-180^{\circ}$ driving way is better than L\&HB: $0^{\circ}-180^{\circ}$ and VB: $0^{\circ}$ driving way, as for, "L" represents the driving way of longitudinal (or axial) vibration type or mode. "HB" represents the driv-

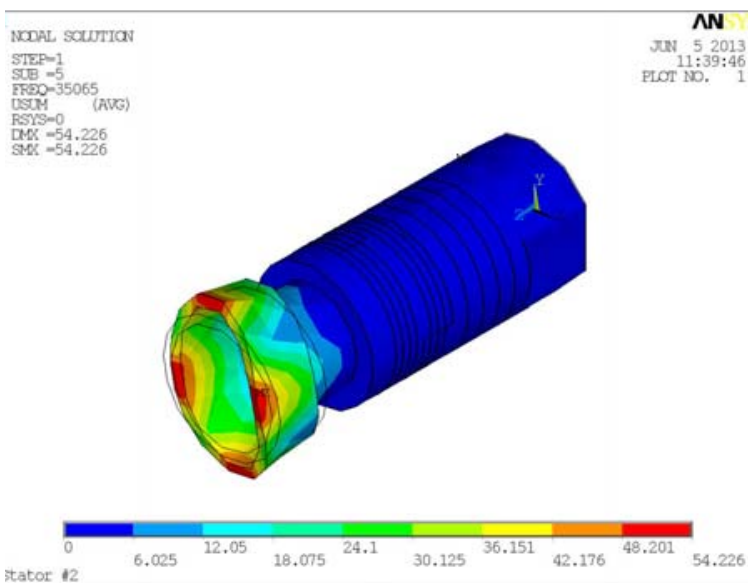

Figure 12. The best vibration mode of the \#2 composite type piezoelectric stator.
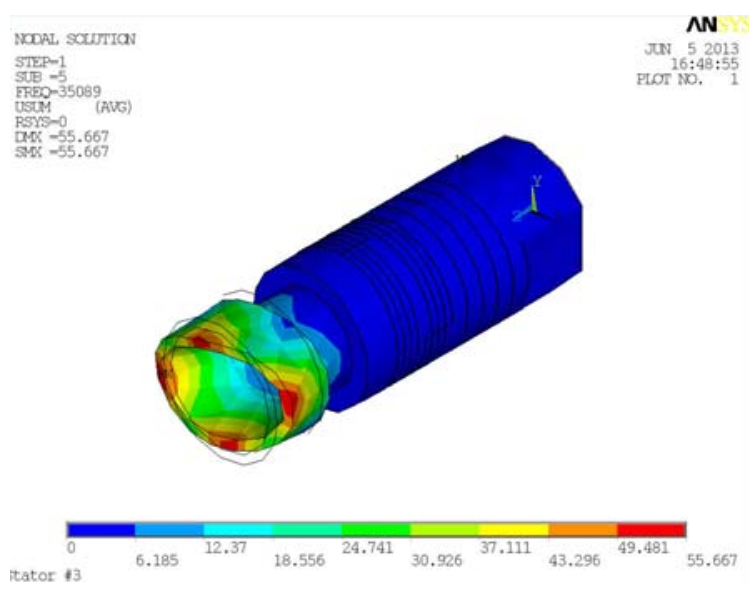

Figure 13. The best vibration mode of the \#3 composite type piezoelectric stator.

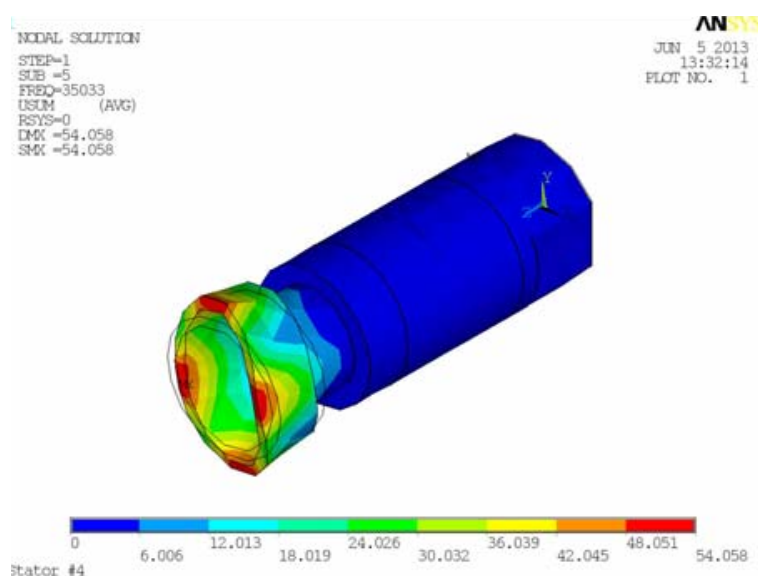

Figure 14. The best vibration mode of the \#4 composite type piezoelectric stator.

ing way of horizontal bending vibration type or mode. "VB" represents the driving way of vertical bending vibration type or mode. " 0 " or $180^{\circ}$ " represents the driving phase angle. 

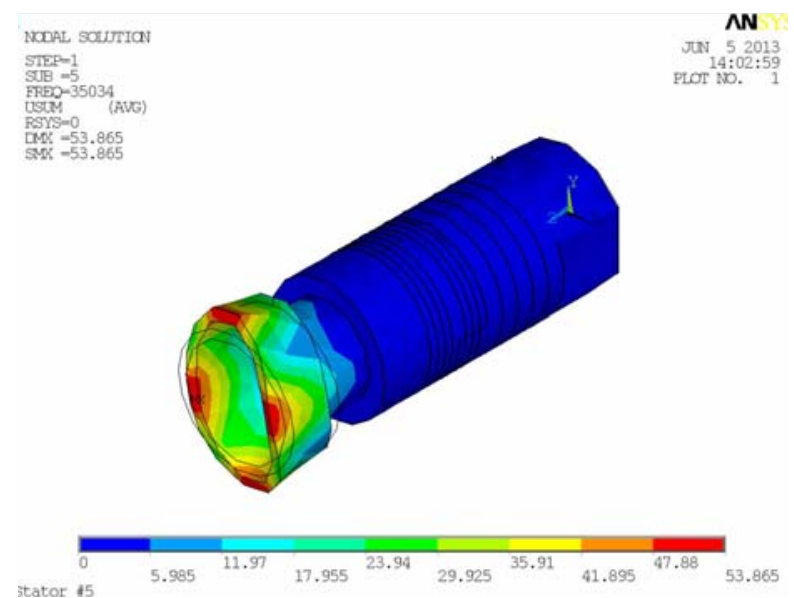

Figure 15. The best vibration mode of the \#5 composite type piezoelectric stator.

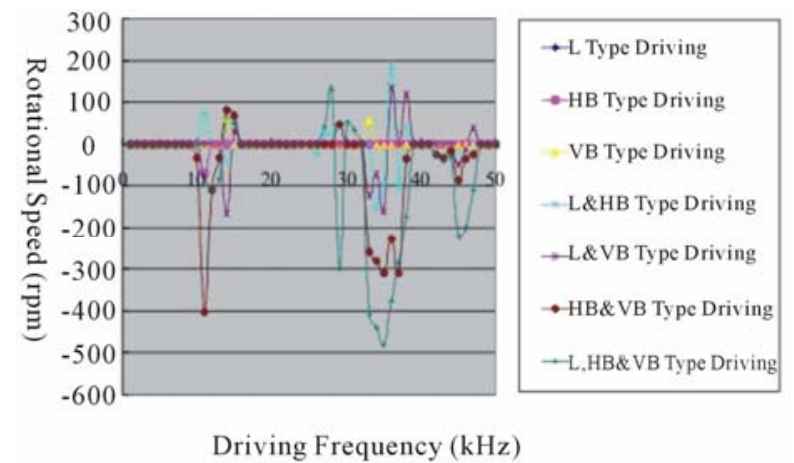

Figure 16. The rotational speed relative to the driving frequency by different driving ways testing of the \#1 composite type piezoelectric stator under conditions of $180 \mathrm{~V}_{\mathrm{p} \text {-p }}$ driving voltage, $35 \mathrm{kHz}$ driving frequency, $12.1 \mathrm{gw}$ preload and gear type rotor.

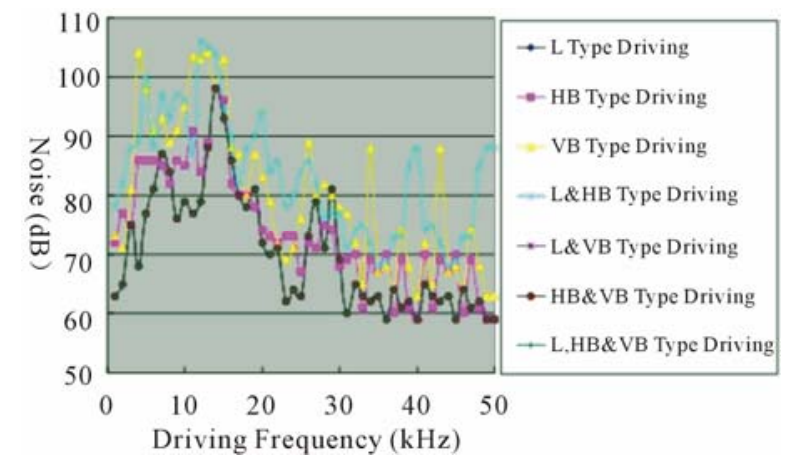

Figure 17. The noise relative to the driving frequency by different driving ways testing of the \#1 composite type piezoelectric stator under conditions of $180 \mathrm{~V}_{\mathrm{p} \text {-p }}$ driving voltage, $35 \mathrm{kHz}$ driving frequency, $12.1 \mathrm{gw}$ preload and gear type rotor.

7) As shown in Figures 20 to 21, we find the rotational speed is proportional to the driving voltage, and is inversely proportional to the loading, where the rotational speed and loading ability of the \#1 piezoelec-

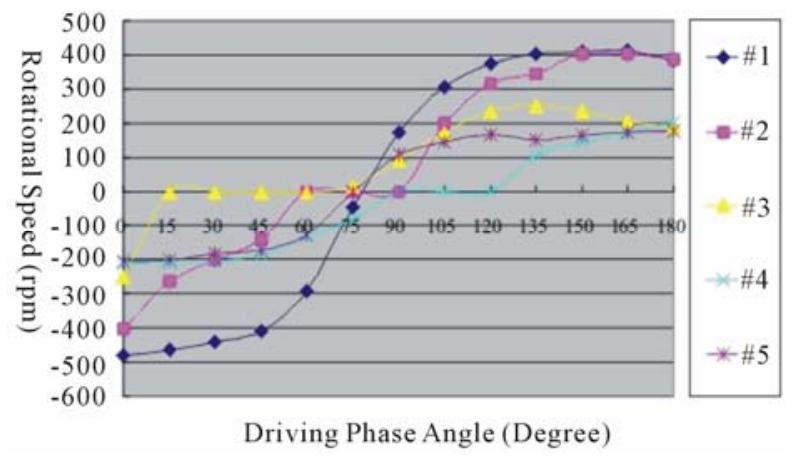

Figure 18. The rotational speed relative to the driving phase angle of \#1 - \#5 composite type piezoelectric stator under conditions of $L \& B 1: 00$ and $B 2: 00 \sim 1800$ driving way, 180 $\mathrm{V}_{\mathrm{p}-\mathrm{p}}$ driving voltage, $35 \mathrm{kHz}$ driving frequency, $12.1 \mathrm{gw}$ preload and gear type rotor.

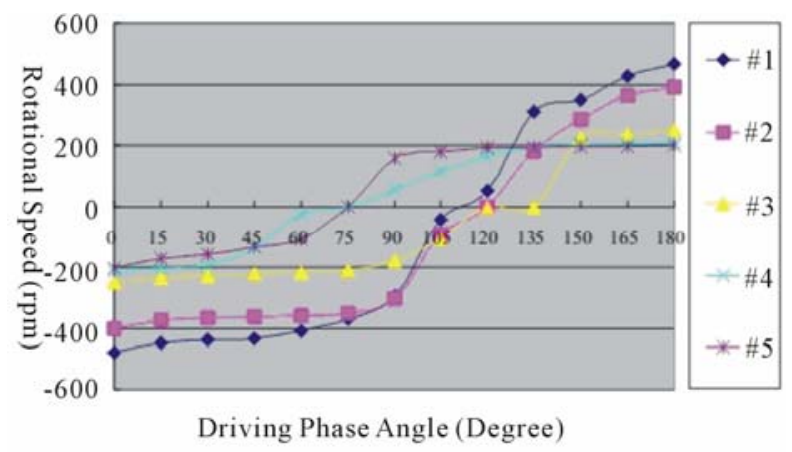

Figure 19. The rotational speed relative to the driving phase angle of \#1 - \#5 composite type piezoelectric stator under conditions of $L$ \& B1:00 - 1800 and B2:00 driving way, 180 $\mathrm{V}_{\mathrm{p}-\mathrm{p}}$ driving voltage, $35 \mathrm{kHz}$ driving frequency, $12.1 \mathrm{gw}$ preload and gear type rotor.

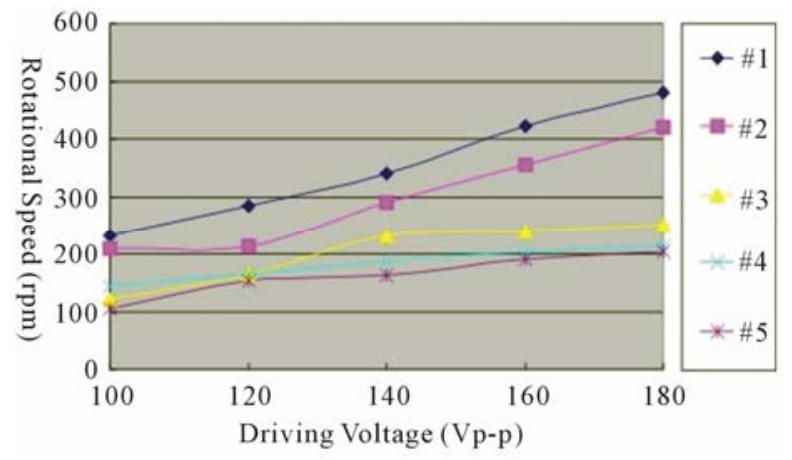

Figure 20. The rotational speed relative to the driving voltage of \#1 - \#5 composite type piezoelectric stator under conditions of $180 \mathrm{~V}_{\mathrm{p}-\mathrm{p}}$ driving voltage, $35 \mathrm{kHz}$ driving frequency, $12.1 \mathrm{gw}$ preload and gear type rotor.

tric stator is better than the other. For rotational speed, the shorter the length of the piezoelectric stator or stator, the rotational speed of the piezoelectric motor is better. As for loading ability, the shorter the length of the piezoelectric stator or stator, the loading ability of the piezoelectric motor is better under the same driving condi- 
tions.

8) Figure 22 shows the experimental results, we found the rotational speed of the gear type rotor (D20Gear) is better than the other under conditions of L\&B1: $0^{\circ}$ and B2: $0^{\circ}$ driving way and $180 \mathrm{~V}_{\mathrm{p}-\mathrm{p}}$ driving voltage. Secondly, the rotational speed of the aluminum type rotor is better the other, in addition to the gear type rotor. As for, the rotational speed of D20Al type rotor approaches zero (only $15 \mathrm{rpm}$ ), means that it is not suitable for the \#3 piezoelectric stator.

\section{Conclusion}

According to the results of the computer simulation analysis, we found that the resonance frequency and the maximum deformation are inversely proportional to the length of the stator. Furthermore, we also find the best vibration mode of each piezoelectric stator landed between the fourth or fifth resonant mode. According to the experimental results, we found that the rotational speed of the driving way of three kinds of vibration modes is better than the other driving ways. In addition, we also found that the average noise of the driving way of three kinds of vibration modes is much lower than the other

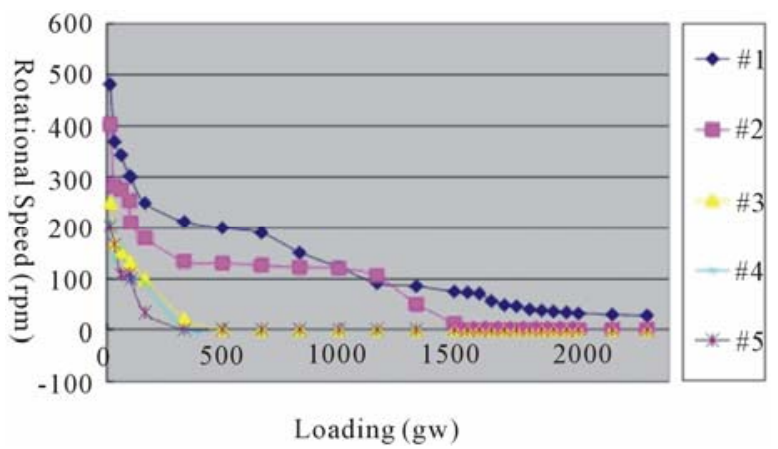

Figure 21. The rotational speed relative to the loading of \#1 - \#5 composite type piezoelectric stator under condition of $180 V_{p-p}$ driving voltage.

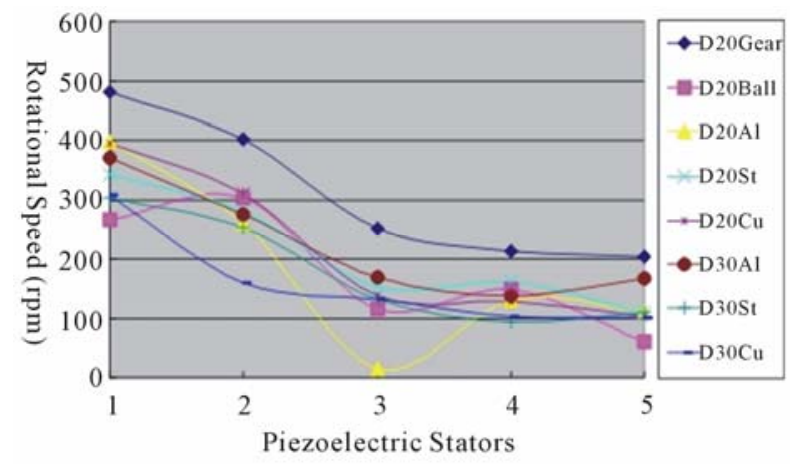

Figure 22. The rotational speed relative to the \#1 - \#5 composite type piezoelectric stator under conditions of $L$ \& $B 1: 00$ and B2:00 driving way, $180 \mathrm{~V}_{\mathrm{p} \text {-p }}$ driving voltage and different type rotors. driving ways. Most importantly, we find the conversion efficiency of the driving phase angle of the \#1 piezoelectric stator (the shortest piezoelectric stator) is better than the other piezoelectric stators. The rotational speed and loading ability of the \#1 piezoelectric stator (the shortest piezoelectric stator) is better than the other piezoelectric stators. Finally, we also found the rotational speed of the aluminum type rotor is better than the other type rotors under the same driving conditions.

\section{Acknowledgements}

This study can be finished smoothly, we should thank for NSC of Taiwan, ROC (Plan No.:NSC101-2221-E-230002).

\section{REFERENCES}

[1] E. N. Brody, S. Ueha and M. Kurosawa, "Ultrasonic Motor,” IEEE Ultrasonics Symposium, 1988, pp. 519-522.

[2] T. Kanda, A. Makino, K. Suzumori, T. Morita and M. K. Kurosawa, "A Cylindrical Micro Ultrasonic Motor using a Micro-Machined Bulk Piezoelectric Transducer," IEEE Ultrasonics Symposium, Vol. 2, 27-28 August 2004, pp. 1298-1301. doi:10.1109/ULTSYM.2004.1418028

[3] K. T. Chau, B. Shi, L. Jing, M.-Q. Hu and Y. Fan, "A Short Cylinder Ultrasonic Motor with Novel Excitation Mode," Industry Applications Conference of 39th IAS Annual Meeting. Conference Record of the 2004 IEEE, Vol. 1, 3-7 October 2004, pp. 360-365.

[4] T. Kanda, A. Makino, K. Suzumori, T. Morita and M. K. Kurosawa, "Characteristics, Modeling and Simulation of a Traveling Wave Ultrasonic Linear Motor," 2004 IEEE Ultrasonics Symposium, Vol. 3, 23-27 August 2004, pp. 2247-2250. doi:10.1109/ULTSYM.2004.1418287

[5] A. Suzuki, M. Kihara, Y. Katsumata, N. Kikuchi and J. Tsujino, "Configurations of Ultrasonic Motors Using Multiple Longitudinal Transducers," IEEE Ultrasonics Symposium, Vol. 3, 23-27 August 2004, pp. 2267-2270. doi:10.1109/ULTSYM.2004.1418292

[6] Y. Ogahara and T. Maeno, "Torque Characteristics Analysis of a Traveling Wave Type Ultrasonic Motor Impressed High Load Torque in Low Speed Range," IEEE International Ultrasonics, Ferroelectrics and Frequency Control Joint 50th Anniversary Conference, 2004, pp. 2271-2274.

[7] Y. Nakagawa, A. Saito and T. Maeno, "Transient Analysis of Bar-type Ultrasonic Motors," Proceedings of 2004 IEEE/RSJ International Conference on Intelligent Robots and Systems, Vol. 2, 28 September-2 October 2004, pp. 1263-1268.

[8] O. Vyshnevskyy, S. Kovalev and J. Mehner, "Coupled Tangential-Axial Resonant Modes of Piezoelectric Hollow Cylinders and Their Application in Ultrasonic Motors," IEEE Transactions on Ultrasonics, Ferroelectrics and Frequency Control, Vol. 52, No. 1, 2005, pp.31-36. doi:10.1109/TUFFC.2005.1397348

[9] T. Kanda, Y. Oomori, A. Makino, K. Suzumori and A. 
Kobayashi, "Design and Testing of Rotors for A Cylindrical Micro-machined Micro Ultrasonic Motor," IEEE Ultrasonics Symposium, San Diego, 29 October-2 November 2005, pp. 301-304.

doi:10.1109/IROS.2007.4399205

[10] A. Kobayashi and T. Kanda, "Driving Performance of a Cylindrical Micro Ultrasonic Motor," Proceedings of the 2007 IEEE/RSJ International Conference on Intelligent Robots and Systems, Vol. 1, San Diego, 29 October-2 November 2007, pp. 3809-3814.

[11] A. Saito, Y. Nakagawa and T. Maen, "Nonlinear Transient Response Analysis of Traveling-Wave Type Ultrasonic Motors," Applications of Ferroelectrics, 17th IEEE International Symposium, Vol. 3, Santa Re, 23-28 February 2008 , pp. 1-2.

[12] T. Ichihara and T. Kanda, "Design and Evaluation of Low-profile Micro Ultrasonic Motors using Sector Shaped Piezoelectric Vibrators," 2008 IEEE/RSJ International Conference on Intelligent Robots and Systems,
Nice, 22-26 September 2008, pp. 588-593.

[13] J.-M. Jou, "A Study on the Multi-Block Piezoelectric Car," 2011 International Symposium on Mechatronic and Biomedical Engineering \& Applications, Taiwan, 8 November 2011, pp. 123-128.

[14] J.-M. Jou, "A Study on the H Type Piezoelectric Car," International Conference on Electric Information and Control Engineering, Lushan, 6-8 April 2012, pp. 42614264.

[15] J.-M. Jou, "A Study on the Piezoelectric Motor of High Actuating Force," 2012 International Symposium on Mechatronic and Biomedical Engineering \& Applications, Taiwan November 2012, pp.169-176.

[16] J.-M. Jou, "A Study on the Rod Type Ultrasonic Motor," Advanced Materials Research, Vol. 716, 2013, pp. 600-607. 